\title{
White matter changes in Alzheimer's disease: a focus on myelin and oligodendrocytes
}

\author{
Sara E. Nasrabady ${ }^{1 *}$, Batool Rizvi ${ }^{4}$, James E. Goldman ${ }^{2,4}$ and Adam M. Brickman ${ }^{3,4}$
}

\begin{abstract}
Alzheimer's disease (AD) is conceptualized as a progressive consequence of two hallmark pathological changes in grey matter: extracellular amyloid plaques and neurofibrillary tangles. However, over the past several years, neuroimaging studies have implicated micro- and macrostructural abnormalities in white matter in the risk and progression of $A D$, suggesting that in addition to the neuronal pathology characteristic of the disease, white matter degeneration and demyelination may be also important pathophysiological features. Here we review the evidence for white matter abnormalities in AD with a focus on myelin and oligodendrocytes, the only source of myelination in the central nervous system, and discuss the relationship between white matter changes and the hallmarks of Alzheimer's disease. We review several mechanisms such as ischemia, oxidative stress, excitotoxicity, iron overload, $A \beta$ toxicity and tauopathy, which could affect oligodendrocytes. We conclude that white matter abnormalities, and in particular myelin and oligodendrocytes, could be mechanistically important in AD pathology and could be potential treatment targets.
\end{abstract}

Keywords: Alzheimer's disease, White matter, Myelin, Oligodendrocyte, Neurodegeneration, Oxidative stress

\section{Introduction}

Alzheimer's disease (AD) is conceptualized as a progressive consequence of two hallmark pathological changes: extracellular neuritic plaques, which are composed of amyloid-beta $(A \beta)$ surrounded by dystrophic neuritic processes, and neurofibrillary tangles, which are intraneuronal aggregates of insoluble cytoskeletal elements, composed mainly of phosphorylated tau protein. These pathological changes are believed to result in neurodegeneration, which can be appreciated with structural neuroimaging as regional and global atrophy [73]. Because of the distribution of this pathology and its associated neurodegeneration, $\mathrm{AD}$ is typically considered a disease of the brain's grey matter. However, over the past several years, neuroimaging studies have implicated micro- and macrostructural abnormalities in white matter in the risk and progression of $\mathrm{AD}$, suggesting that in addition to the neuronal loss characteristic of the

\footnotetext{
* Correspondence: se2351@columbia.edu

${ }^{1}$ Department of Psychiatry, Columbia University, New York, NY, USA

Full list of author information is available at the end of the article
}

disease, white matter degeneration and demyelination may be important pathophysiological features. Myelin loss and the inability of the oligodendrocytes, the cells responsible for the production and maintenance of myelin, to repair myelin damage may be additional central features of $\mathrm{AD}[5,53,55,60]$. Because of the essential role of oligodendrocyte cell lineage in myelin production and remyelination processes, changes in the number of oligodendrocytes or their precursor cells and/or their dysfunction can affect myelin integrity and therefore be potentially implicated in $\mathrm{AD}$ pathogenesis.

The purpose of this review is to discuss the evidence for white matter abnormalities in AD with a focus on myelin damage and oligodendrocyte lineage cells and to review the relationship between white matter changes and the pathological hallmarks of AD. In addition, we discuss whether white matter changes are a secondary result of cortical AD pathology or whether they contribute directly or indirectly to the pathogenesis and clinical manifestation of $\mathrm{AD}$. 


\section{Evidence of white matter abnormalities from imaging studies}

The observation that neuroimaging-defined white matter abnormalities are characteristic of $\mathrm{AD}$ is relatively new. Work from our laboratory, for example, demonstrated that the burden of white matter hyperintensities (WMH), distributed signal abnormalities visualized on T2-weighted magnetic resonance imaging (MRI), predicts incident $A D$ $[18,19,21]$, the rate of cognitive decline among individuals with prevalent $\mathrm{AD}$ [78], and is associated with genetic risk factors for late onset $\mathrm{AD}$ [20]. We recently showed in the Dominantly Inherited Alzheimer's Network that WMH volume is elevated among individuals with autosomal dominant, fully penetrant mutations for AD up to 20 years before the expected onset of symptoms, demonstrating that white matter abnormalities are indeed a core feature of AD. Furthermore, the appearance of WMH in these patients emerges contemporaneously with AD-related cerebrospinal fluid (CSF) amyloid and tau abnormalities [49]. WMH severity also correlates with CSF levels of $A \beta 1-42$ in preclinical AD [49] and predicts increasing CSF tau levels in individuals with mild cognitive impairment [79]. White matter hyperintensity severity is associated with cerebrospinal fluid (CSF) amyloid levels independent of vascular risk factors [71].

The important role of vascular disease in the development of white matter damage should be emphasized. White matter hyperintensities tend to be distributed in brain areas with relatively low perfusion levels, particularly in the deep, periventricular white matter. The density of vessels in these areas decreases both with normal aging and in AD [23], consistent with reports of decreased blood flow to white matter [69], which could cause hypoxic/ischemic damage in these areas. White matter hyperintensities are related to small vessel disease, and inflammation $[26,61,64]$, but comprehensive analysis of postmortem tissue in areas known to be affected by WMH, including evaluation of possible hypoxic damage to oligodendrocyte lineage cells, has not been completed. A recent study reported that parietal WMH pathogenesis in $\mathrm{AD}$ is related to axonal loss, through Wallerian-like degeneration, which corresponds to cortical phosphorylated tau burden, and demyelination in patients with $\mathrm{AD}$ but to vasculopathy and ischemia (by sclerotic index as a marker of small vessel disease and myelin associated glycoprotein to proteolipid protein ratio as a measure of hypoperfusion) in individuals without $\mathrm{AD}$, suggesting that some degree of WMH is secondary to neurodegeneration in the context of $\mathrm{AD}$ [57]. However, neuroimaging studies showed that white matter networks are defective in preclinical AD, at a time when neurodegenerative changes, cortical atrophy, or cortical glucose reduction were not apparent [33]. Vascular and blood brain barrier (BBB) impairments, small hemorrhagic lesions and buildup of iron have been reported in the brains of $\mathrm{AD}$ patients even in the preclinical stages of the disease [86].

\section{Histopathological evidence of white matter abnormalities} The neuroimaging studies establish that there is some degree of white matter abnormality in the context of $\mathrm{AD}$, which may be radiological manifestations of more widespread white matter pathological abnormalities. White matter hyperintensities have been associated histopathologically with myelin pallor, myelin loss [31, 38] (as shown in Fig. 1) and the loss of myelinated axons, as well as changes in arterial adventitia in deep white matter [68]. In our aim to review the widespread white matter abnormalities, we focus on the changes in the myelin sheath and oligodendrocyte lineage cells.

\section{Myelin damage}

In the normal development of the central nervous system (CNS), different brain regions are myelinated at different times. Myelination begins in the fourth month of human embryonic development and continues until the third or fourth decade of life $[22,47]$. In general, the spinal cord and brain stem myelinate earlier, while other areas, such as the telencephalon, the entorhinal cortex, hippocampus and the amygdala myelinate later $[17,30]$. Diffusion tensor imaging studies show the development of association tracts in post-adolescent subjects [47]. In addition, there is a particular susceptibility for demyelination in areas that are myelinated at older ages, a phenomenon referred to as "neuropathologic retrogenesis" [8, 12, 17, 66, 76]. Myelin loss has been observed consistently in $\mathrm{AD}$ and the latermyelinated areas are also most vulnerable $[13,36,65]$. They demonstrate significantly greater myelin loss compared with areas that myelinate earlier [6]. Analysis of postmortem brain tissue of $\mathrm{AD}$ patients has revealed that the white matter is altered chemically, compared with that of patients without dementia: the amounts of total protein, myelin basic protein (MBP), myelin proteolipid protein (PLP), Cyclic nucleotide phosphohydrolase (CNPase), and cholesterol is significantly decreased, indicating a loss of myelin. White matter fatty acid ratios are also altered in $\mathrm{AD}$ [67].

White matter and myelin changes in $\mathrm{AD}$ need to be taken with respect to changes during aging. For example, the overall hemispheric white matter volume decreases with age [50]. How much of this is due to changes in water content or water infusibility is not completely clear [42]. However, a decrease in the total length of myelinated fibers, reaching a $45 \%$ decrease from 20 to 80 year-old individuals and the appearance of thinner axons has been reported [50]. Thus, a number of investigations conclude that with age, myelin production by oligodendrocytes continues but leads to thinner myelin sheaths and shorter internodes [50]. Axon caliber decreases in experimental models of demyelination and remyelination [52]. Thinner 

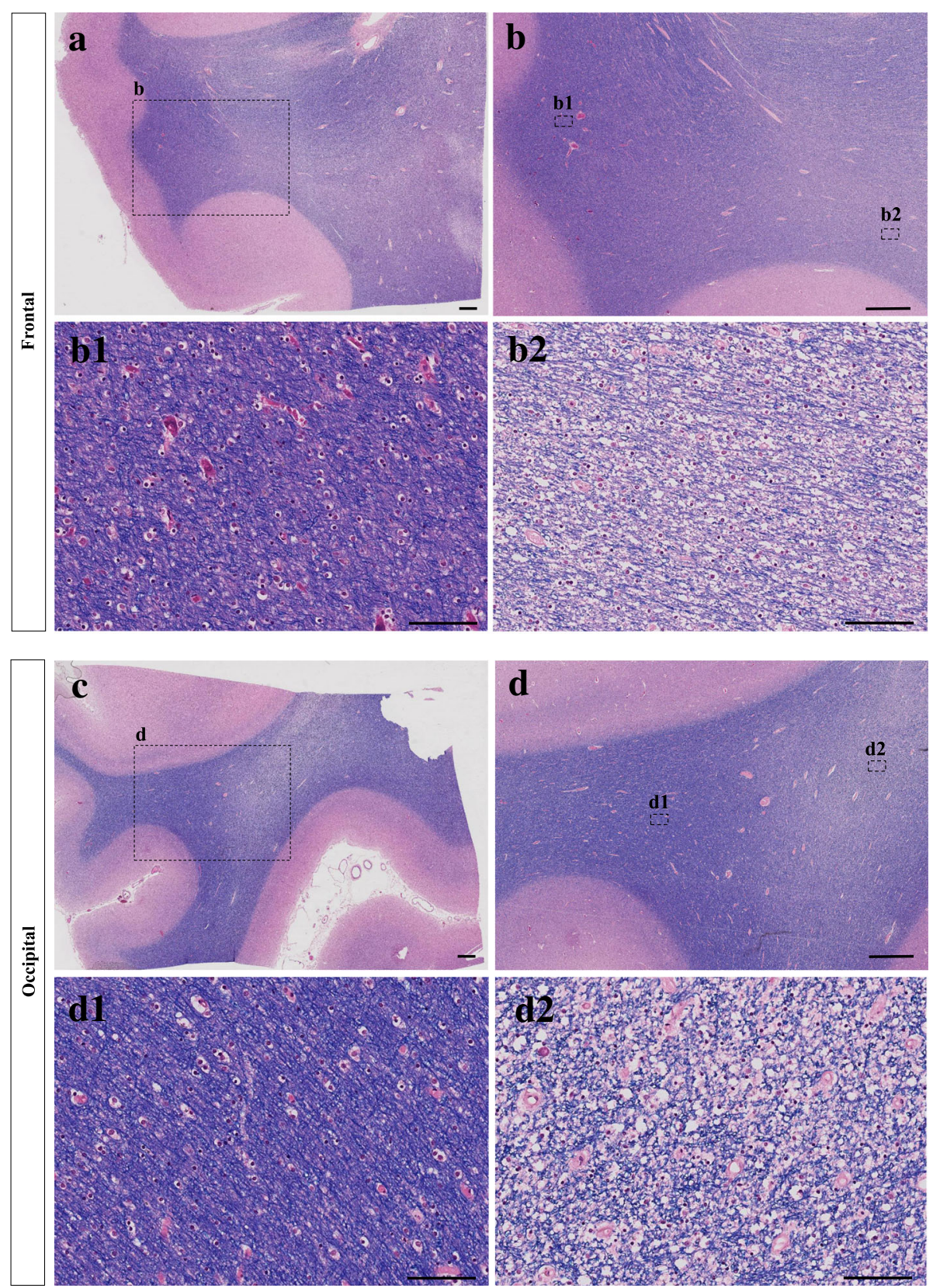

Fig. 1 This figure demonstrates examples of white matter myelin loss in brain sections from a patient with Alzheimer's disease. Tissues from frontal and occipital areas are stained with Luxol fast blue-hematoxylin and eosin (LHE). b2 and b1 represent the regions with and without myelin pallor in the frontal area, respectively. $\mathrm{d} 2$ and $\mathrm{d} 1$ represent the regions with and without myelin pallor in the occipital area, respectively. The scale bars in images $\mathbf{a}, \mathbf{b}, \mathbf{c}$ and $\mathbf{d}$ are $1000 \mu \mathrm{m}$. The scale bars in images b1, b2, d1 and $d 2$ are $100 \mu \mathrm{m}$

myelin sheaths and smaller axons can lead to functional white matter deficits due to conduction failure and by a greater vulnerability to trauma, oxidative stress, or $\mathrm{A} \beta$ toxicity [5]. Axonal loss and demyelination are both associated with white matter abnormalities in $\mathrm{AD}$ and are predictors of severity of white matter abnormalities [57]. Future studies with the aim of preventing or repairing myelin damage could elucidate the impact of white matter changes as one of the core pathologies of AD.

\section{Abnormalities of oligodendrocyte lineage cells in AD}

The primary role of oligodendrocytes is to produce myelin, but they also play a supportive, modulatory and regulatory role for neurons, including the production of neurotrophic factors, inhibition of neurite growth, and stabilization of neuronal connectivity $[44,70]$. The adult central nervous system contains both precursor cells for oligodendrocytes in addition to mature, myelinating cells [10]. Oligodendrocyte 
precursor cells (OPCs) in the adult central nervous system are capable of proliferating and migrating and effecting new myelination after demyelinating insults. Animal studies have shown that during adulthood, oligodendrocytes are generated from ventricularsubventricular zone and the new oligodendrocytes progenitors migrate to white matter tracks from there [59]. Mature human oligodendrocytes in the condition of being deprived from their myelin sheath may return into their previous subtype capacity and change their phenotype and their myelination program [37]. The different oligodendrocyte lineage cells express changes in morphology during their development and maturation [10]. Figure 2 shows an example of oligodendrocyte distribution throughout white matter areas in an adult postmortem human brain. In mammals, OPCs, by presence of intrinsic hypoxia-inducible factor (HIF) signaling, control white matter angiogenesis, axonal integrity, and the onset of myelination at postnatal stages [85]. Oligodendrocytes are able to modulate ion homeostasis in the axon environment [60]. OPCs are the specific glial cells that directly make synapses with neurons; they build synapses with glutamatergic neurons in the hippocampus (rat) [15], cortex (mouse) [24], white matter tracks (rat) [46] and other areas. However, they only make postsynaptic connection with neurons. The behavior of OPCs can be controlled by neurotransmitters and by surrounding neuronal demands. For example, in the presence of higher neural activity, oligodendrocytes change the amounts of myelin sheaths, which affects the
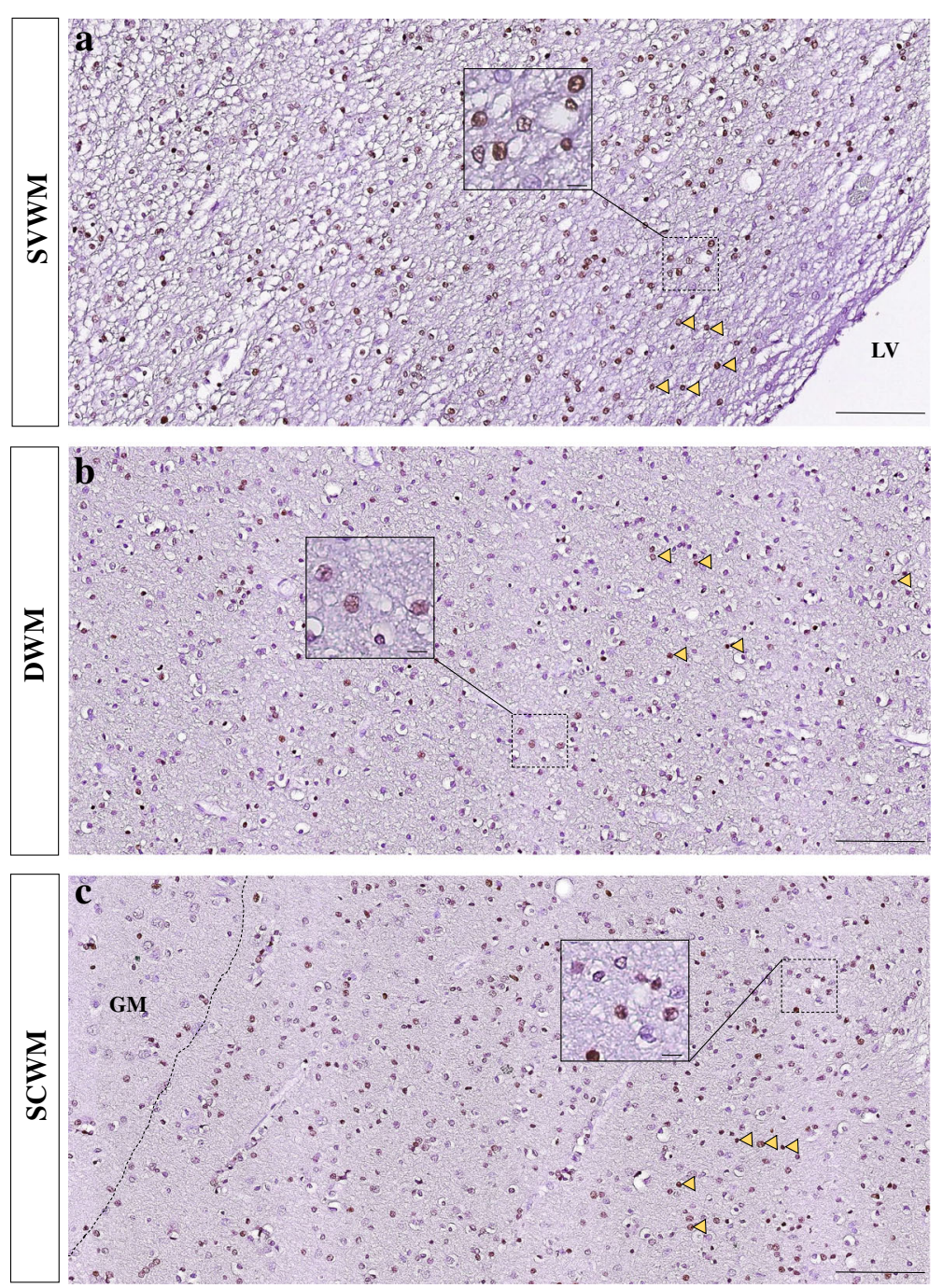

Fig. 2 An example of Olig2+ oligodendrocyte distribution throughout the white matter from a neurologically-healthy adult, postmortem brain. The insets show Olig2+ nuclei at higher magnification. H\&E counterstaining. Arrowheads: Olig2+ nuclei (brown). Dashed line: the border of white and grey matter. LV: lateral ventricle; SWWM: subventricular white matter; DWM: deep white matter; SCWM: subcortical white matter; GM: grey matter. The scale bars in $\mathbf{a}, \mathbf{b}$ and $\mathbf{c}$ are $100 \mu \mathrm{m}$ and the scale bars in the insets are $10 \mu \mathrm{m}$ 
electrical transmission in the neuronal network [32]. We could speculate that neuronal AD pathology, which is characterized by neuronal and axonal dysfunction, could alter the amounts of myelin produced by oligodendrocytes. This dynamicity of myelin and oligodendrocytes thus could ultimately affect behavior [58].

A number of human and animal studies investigated oligodendrocyte changes in $\mathrm{AD}$. In one study, 6-8month-old APPPS1 mice showed an increase in the numbers of OPCs, while the number of Olig2+ cells in postmortem tissues of $\mathrm{AD}$ patients was decreased [11]. Another study reported a higher number of MAP-2 positive remyelinating oligodendrocytes in the areas adjacent to periventricular white matter lesions and a higher number of PDGFR- $\alpha$ positive OPCs in white matter lesions [74]. In a PS1 knock-in mouse model, increased vulnerability and death of oligodendrocytes due to glutamate and $A \beta$ were demonstrated and these cells showed a deficit in calcium regulation [60]. This study suggests that the abnormalities of oligodendrocytes in the presence of a PS1 mutation could be an early event in the disease course. Another study demonstrated that MBP and the number of myelinating oligodendrocytes were decreased in 6-month old triple transgenic mice (3xTg-AD), the number of immature oligodendrocytes remained unchanged and mature non-myelinating cells were increased [29]. The authors reported that myelinating oligodendrocytes are highly sensitive to oxidative stress due to their higher metabolic demand, higher iron, and lipid content. Reduction of the diameter of oligodendrocyte nuclei in $\mathrm{AD}$ patients in parahippocampal white matter was also reported [35] while the mean nuclear diameter of neurons remained unchanged. Alzheimer's-related changes in oligodendrocytes for human studies and animal models are summarized in Table 1.

One of the frequently accepted themes related to oligodendrocyte damage in $\mathrm{AD}$ is that these cells suffer from oxidative stress, which can be produced by a wide range of factors. The adult CNS contains oligodendrocyte precursor cells, which can be mobilized to differentiate into myelinating oligodendrocytes [10]. Oxidative stress impairs the differentiation of OPCs, in part by decreasing the levels of expression of genes that promote oligodendrocytes differentiation, such as Shh, Sox10 and HDAC3 [34]. In cell culture, pre-oligodendrocytes show a sensitivity to oxidative stress and glutathione depletion [2]. In rat cell cultures, low antioxidant content and high iron capacity, in addition to excitotoxicity through metabotropic glutamate receptors, makes oligodendrocytes more vulnerable to oxidative stress $[27,77]$. Other factors affecting oligodendrocytes are listed below.

$A \beta$ and tau: Several studies suggest that $A \beta$ is toxic to oligodendrocytes [28, 29, 41, 48, 84]. For example, a cell culture study of rat oligodendrocytes demonstrated that $\mathrm{A} \beta$-induced oxidative stress can drive oligodendrocyte death and dysfunction [84]. This study also showed that mitochondrial DNA damage and the consequent NF-kB and AP- 1 activation are other possible mechanisms of A $\beta$ toxicity for oligodendrocytes [84]. Note that although amyloid plaques are exceedingly rare in $\mathrm{AD}$ white matter, the levels of soluble $A \beta$ are elevated in the white matter [25]. Thus, a direct exposure of white matter oligodendrocytes to increased amounts of $A \beta$ is likely. Although there are toxic effects of $A \beta$ on oligodendrocytes, clinical trials that have aimed to remove the $A \beta$ plaque in symptomatic $\mathrm{AD}$ patients, did not prevent the progressive neurodegeneration and cognitive decline in $\mathrm{AD}$ patients [39, 72]. These findings suggest that this toxic effect needs to be targeted earlier or it could not be the only pathology leading to cell death and atrophy in symptomatic patients. In addition to the effects of amyloid pathology, the impact of tau pathology on white matter needs to be considered. Tau can affect the normal function of neurons through a toxic gain of function or a loss of its normal function in stabilizing microtubules. Although severe neocortical tauopathy occurs in later stages of $\mathrm{AD}$ and mostly affects grey matter, phosphorylated tau transforms into neurofibrillary tangles in neurons as well as glial tangles in astrocytes

Table 1 This table summarizes the studies, the specimen that was used, and oligodendrocyte alterations in AD animal models and human

\begin{tabular}{|c|c|c|c|c|}
\hline The model and specimen & Oligodendrocyte changes & & & Source \\
\hline PS1 knock-in mouse & Vulnerability and death of OLs & & & Pak et al. 2003 \\
\hline Postmortem AD & $\begin{array}{l}\text { Increased MAP-2 positive remyelinating } \\
\text { OLs adjacent to WM lesions }\end{array}$ & $\begin{array}{l}\text { Increased PDGFR- a positive } \\
\text { OPCs in WM lesions }\end{array}$ & $\begin{array}{l}\text { No change in Myelinating } \\
\text { OLs in deep white matter }\end{array}$ & Simpson et al. 2007 \\
\hline $3 \times T g-A D$ mouse & Decreased myelinating OLs & No change in immature OLs & $\begin{array}{l}\text { Increased mature non- } \\
\text { myelinating OLs }\end{array}$ & Desai et al. 2010 \\
\hline Postmortem AD & $\begin{array}{l}\text { Reduced OLs nuclear diameter } \\
\text { in parahippocampal white matter }\end{array}$ & & & Gagyi et al. 2011 \\
\hline APPPS1 mouse & Increased OPCs number & & & Behrendt et al. 2013 \\
\hline Postmortem AD & Decreased Olig2+ & & & Behrendt et al. 2013 \\
\hline
\end{tabular}

It depicts the verity of the results in different animal models and human studies. PS1 Presenelin-1, OL oligodendrocyte, MAP microtubule associated protein, $P D G F R$ platelet-derived growth factor receptor, OPCs oligodendrocyte progenitor cells, WM white matter, $3 \times T g-A D$ triple transgenic AD mouse model. APPPS1 mouse mouse with both APP and PS1 transgenes 
or oligodendroglia [4]. Furthermore, phosphorylated tau in grey matter is associated with white matter abnormalities and demyelination in $\mathrm{AD}$ patients $[56,57]$. The increased levels of calpain2 in the AD white matter, an indicator of axonal loss, was shown to be associated with increased cortical phosphorylated tau and amyloid [57] and the phosphorylated tau showed to be a predictor for white matter hyperintensities [56].

Iron: During myelination, oligodendrocytes require 2-3 fold higher energy levels than other cell types in the CNS to produce such an extensive amount of membrane. Oligodendrocytes synthesize cholesterol, a process that is highly metabolically demanding, making them vulnerable to hypoperfusion, excitotoxicity, heavy metals, and free radicals that induce oxidative stress. Oligodendrocytes have the highest iron content of all cell types, which increases with age and even further in $\mathrm{AD}$ [5]. Oligodendrocytes at all stages of their differentiation, compared with other glial cells contain smaller amounts of antioxidant agents (e.g. glutathione peroxidase) and only half of the glutathione reductase activity [43]. Thus, a high iron content and a low antioxidant content make oligodendrocytes one of the most vulnerable cell classes to oxidative stress in the CNS. If oxidative stress is exacerbated by age, it may lead to increased cell damage [81]. Bartzokis by comparing a map of cortical myelination with maps of $A \beta$ deposition hypothesized that age-associated myelin breakdown leads to iron release from oligodendrocytes and that this iron release promotes $A \beta$ oligomerization in the parenchyma [7].

Hypoxia/Ischemia: Deep white matter areas lie at the ends of the CNS arterial circulation, making them susceptible to decreases in blood flow and oxygenation. Some anterior and posterior white matter lies in watershed zones between the anterior cerebral and middle cerebral arteries and middle cerebral and posterior cerebral arteries respectively. Vascular pathology in these regions is greater in patients with $\mathrm{AD}$ than in individuals without dementia [23, 69]. Late-stage oligodendrocyte progenitors are more sensitive to hypoxic or ischemic damage than early-stage progenitors and more mature oligodendrocytes [3]. A recent rodent study, using single cell RNA sequencing, identified a population of oligodendrocyte precursors as vascular and leptomeningeal cells. These OPCs are located along vessels and they show similarities with pericyte lineage cells [51]. In addition, to emphasize the importance of relationship between vascular system and oligodendrocyte lineage cells Tsai showed that those OPCs require the physical infrastructure provided by the vascular system to facilitate their migration during development [80].

Excitotoxicity: In general, oligodendrocytes show a great vulnerability to excessive ATP and/or activation of glutamate receptors [55]. Oligodendrocytes express a wide variety of receptors and membrane channels (e.g. ionotropic glutamate and ATP receptors, ligand gated $\mathrm{Ca}^{2+}$ channels and P2x7 receptors). Because of the lack of the GluR2 subunit in oligodendrocyte AMPA receptors, there is a higher permeability to $\mathrm{Ca}^{2+}$ ions compared with neurons [54]. Another example is the sustained activation of p2x7 receptors in oligodendrocytes due to excitotoxicity or to high levels of ATP/ADP/AMP, which leads to excessive $\mathrm{Ca}^{2+}$ in the cytosol and the activation of apoptosis through caspase-3 activation. Extensive activation of these receptors can result in oligodendrocyte damage and subsequently myelin destruction. Back and colleagues showed maturation-dependent vulnerability of oligodendrocytes caused by intracellular glutathione depletion [2]. In addition, as we mentioned, oligodendrocytes and myelin damage due to excitotoxicity and calcium dysregulation could be an early pathological feature of AD $[45,60]$.

DNA damage: Age related DNA damage in myelinating oligodendrocytes may contribute to myelin loss [81, 82]. Postmortem analysis of white matter lesions obtained from aging individuals shows the presence of oxidative damage (8-OHdG immunoreactivity) in oligodendrocyte nuclear DNA. These cells are also positive for senescence markers such as SA- $\beta$-gal [1]. In older adults, excessive DNA damage occurs in vulnerable oligodendrocytes and the DNA repair mechanism becomes overwhelmed. Studies of changes in genomic integrity and genomic instability of oligodendrocytes in the white matter of patients and animal models could illuminate the role of oligodendrocyte in white matter damage and pathology of $\mathrm{AD}[81,82]$. In addition, oligodendrocyte lineage transcription factor 2 (Olig2) is located on chromosome 21 which is $6.8 \mathrm{Mb}$ telomeric of the amyloid precursor protein (APP) gene. The possibility of these two genes interacting in a context of the disease needs to be studied [75].

\section{Discussion}

A variety of structural, histopathological and biochemical pathologies take place in the white matter of $\mathrm{AD}$ patients (summarized in Fig. 3). In this review, we have tried to answer two questions:

\section{What changes occur in white matter in the course of $A D$ and what is the relationship between these changes and the pathological hallmarks of the disease?}

Radiological, pathological, and molecular changes occur in the white matter of $\mathrm{AD}$ patients. Radiological markers of white matter damage occur as early as 22 years before the estimated age of symptom onset in humans who carry $\mathrm{AD}$ mutations [49]. These white matter changes are believed to reflect demyelination and axon damage [63]. It is possible that the oligodendrocytes or the precursors responsible for remyelination of these areas are altered in number and in DNA stability or are functionally less efficient in the presence of genetic changes, oxidative stress, increased iron 


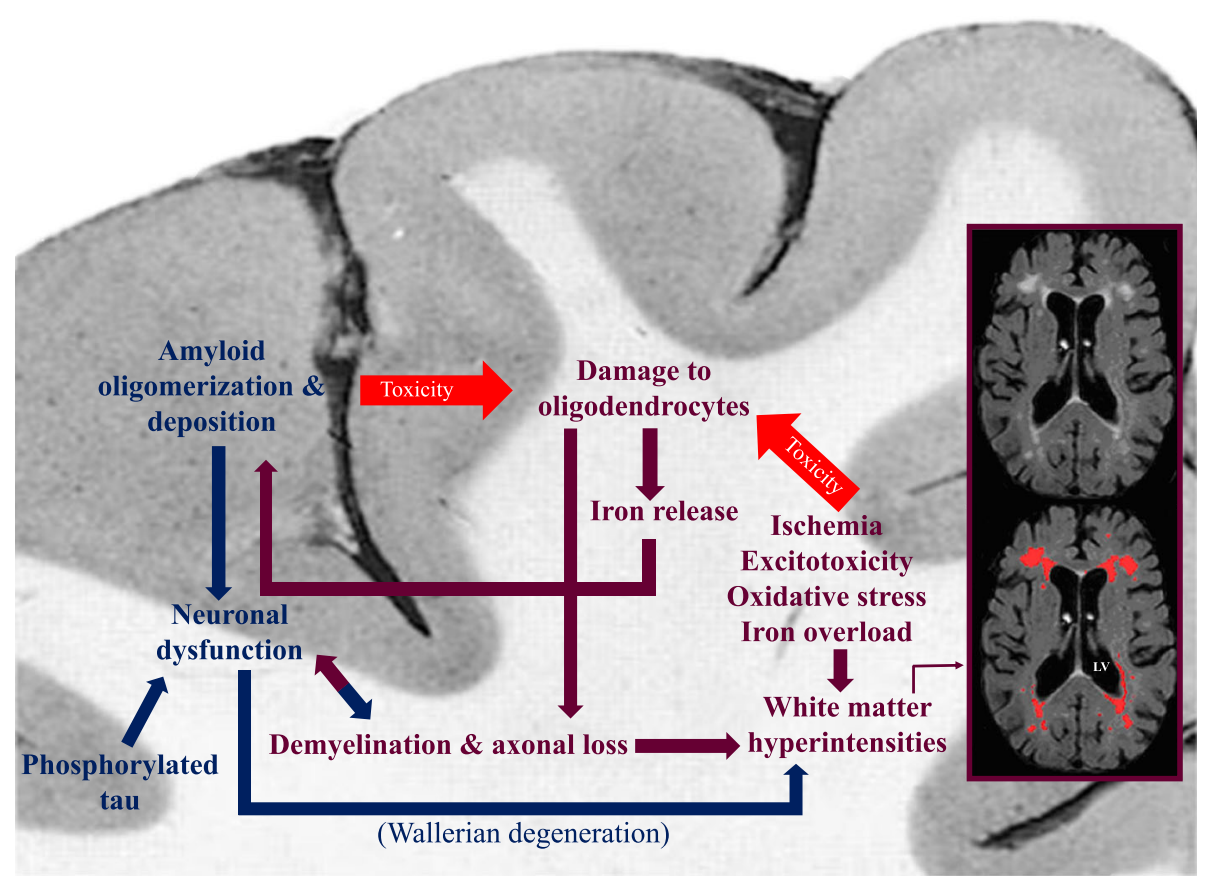

Fig. 3 This figure summarizes the pathological cascades, and their relation with each other, occurring during the development of Alzheimer's disease in white matter and cortex. While ischemia, excitotoxicity, oxidative stress, and iron overload in white matter damage oligodendrocytes, on one hand, and amyloid toxicity affects them, on the other hand, the iron released from damaged oligodendrocytes promotes amyloid polymerization and deposition in grey matter. The consequent demyelination and axonal loss result in further white matter damage and neuronal dysfunction. Neuronal dysfunction is also a result of amyloid deposition in cortex and a proposed cause for white matter abnormalities in AD patients. White matter hyperintensities are labelled with red in the MRI (FLAIR) scan of an AD patient. Blue arrows: direction of the damages originating in grey matter. Maroon arrows: direction of the damages originating in white matter. LV lateral ventricle

levels, and vascular pathology $[5,81]$. In addition to gross white matter damage in $\mathrm{AD}$, there are chemical alterations marked by loss of proteins and cholesterol. The decreases in the levels of myelin proteins, such as myelin basic protein (MBP), myelin proteolipid protein (PLP) and CNPase, in white matter reflects the changes in oligodendrocytes and myelin sheaths. In animal models of $\mathrm{AD}$, the white matter disruption and changes in myelin marker expression are among the earliest pathological changes [16, 30]. Although white matter changes are believed to be partly related to neuronal degeneration in the cortex [57], there is also evidence that oligodendrocyte and myelin pathology, which are detected in $\mathrm{AD}$ mouse models, are affected prior to appearance of amyloid and cortical pathology. It is not clear if these changes are independent of cortical pathology or the cortical structural damages are beyond the detection limits of methods at early stages of the disease $[29,30,40]$ and subtle neurodegenerative changes could precede or promote white matter changes even if they are not detectable with conventional methods. In terms of therapeutic implications, contemporary clinical trials have focused on the removal of fibrillar forms of amyloid protein as a primary target, motivated by the "amyloid hypothesis" that has dominated the field's conceptualization of the disease for many years [73]. Accordingly, interventions that target the removal of amyloid would arrest the progression of disease and improve cognitive outcomes. However, to date, clinical trials aimed to clear $\mathrm{A} \beta$ plaques in $\mathrm{AD}$ have not resulted in clinical improvement or reduction in the rates of disease progression. New strategies for disease treatment and prevention are therefore necessary. The consistent observations that implicate white matter abnormalities in $\mathrm{AD}$ pathogenesis and progression point to opportunities to target potential novel mechanisms implicated in the disease.

\section{Are the clinical changes in $A D$ secondary only to the cortical hallmarks of the disease or do white matter abnormalities contribute directly or indirectly to the disease?}

Beside amyloid hypothesis as the cause of $\mathrm{AD}$, it is crucial to note that there is a weak association between amyloid plaques and $\mathrm{AD}$ symptoms [5]. Further, senile plaques can be found in about $20-40 \%$ of older adults without symptoms of dementia and cognitive impairment [14, 62]. As discussed above, myelin loss contributes to cognitive decline in humans $[67,83]$ and in $\mathrm{AD}$ animal models, early changes in white matter are followed by the first cognitive impairment detected after intracellular accumulation of $A \beta$ but before $A \beta$ plaques 
appear [29]. Altering axonal conduction by demyelination or axonal damage could directly and/or indirectly affect cognition. Future studies with the aim of repairing myelin loss could clarify the impact of white matter changes on AD pathogenesis and may have therapeutic benefit. In addition, dysfunctional oligodendrocytes early in the course of the disease may not be able to play a protective role for neurons and their axons. Hence, the process of remyelination and myelin repair will be affected. Signal conductivity, and synchronicity of impulses, which are required for information processing between neurons, depend on the amount of myelin produced by oligodendrocytes and therefore will be affected [10]. In general, a number of animal AD model studies suggest that white matter pathology emerges prior to appearance of cortical plaques and tangles [29, 30, 40]. Human studies with autosomal dominant forms of $\mathrm{AD}$ suggest that $A \beta$ levels begin to change as early as 2530 years prior to symptom onset, followed by tau pathology about 15 years prior to symptom onset, cerebral hypometabolism, brain atrophy, and cognitive and functional deficits $[9,29]$. As noted above white matter abnormalities are also early findings in these patients [49], but causal relationships among $\mathrm{AD}$ biomarkers in humans are difficult to infer even from observed temporally-ordered observations; white matter changes appear to emerge contemporaneously with other $\mathrm{AD}$ pathology, but it is unclear if one is causing the other. Studies of 3xTg-AD triple transgenic $\mathrm{AD}$ mice show that the first pathological features start to appear in 2 to 6-month old mice as white matter disruption and changes in myelin marker expression in the hippocampus and entorhinal cortex. At this age, the mice do not show learning or memory deficits $[16,30]$. Cognitive impairment emerges after at around 3 to 6-months of age [29]. The studies discussed regarding vascular insufficiency in white matter suggest that the white matter pathology is not caused by cortical pathology. On the other hand, neuronal accumulation of tangles and neuronal death will lead to axonal loss in white matter [57]. It is not clear how this would produce white matter hyperintensities in deep white matter, however, it could well contribute to a more widespread decrease in axons and myelin.

In conclusion, the various observations suggest that white matter abnormalities and in particular impaired myelin and oligodendrocytes could promote cognitive impairment and $\mathrm{AD}$ pathology and could be the important targets for studying and early treatments of AD. Future studies with the aim of repairing myelin damage, beside other efforts focused on the hallmark of Alzheimer's disease, could elucidate the impact of white matter changes as one of the core pathologies of AD.

\section{Abbreviations}

3xTg-AD: triple transgenic AD mice model; AD: Alzheimer's disease; AP-

1: activator protein 1; ATP: adenosine triphosphate; $A \beta$ : amyloid-beta;
BBB: blood brain barrier; CNPase: cyclic nucleotide phosphohydrolase; CNS: central nervous system; CSF: cerebrospinal fluid; HDAC3: histone deacetylase 3; HIF: hypoxia-inducible factor; MBP: myelin basic protein; MRI: magnetic resonance imaging; NF-kB: nuclear factor kappa-light-chainenhancer of activated B cells; OPC: oligodendrocyte precursor cell; P2X7 receptors: P2X purinoceptor 7; PLP: myelin proteolipid protein; Shh: sonic hedgehog; Sox-10: SRY-related HMG-box; WMH: white matter hyperintensity

\section{Acknowledgements}

This work was supported by grants from the Alzheimer's Association, the Taub Institute at Columbia University, the Mary E. Groff Surgical Medical Research and Education Charitable Trust Groff Foundation, and NIH (P50 AG008702). Dr. Nasrabady is supported by NIH T32 grant (MH 20004-19), Division of Late-Life NeuroPsychiatric Disorders, Department of Psychiatry.

Availability of data and materials

The manuscript has no associated data.

\section{Authors' contributions}

SEN, JEG and AMB conceptualized the review, drafted the manuscript, read and approved the final manuscript. BR contributed towards the creation of the figures, read and approved the final manuscript.

Competing interests

The authors declare that they have no competing interests.

\section{Publisher's Note}

Springer Nature remains neutral with regard to jurisdictional claims in published maps and institutional affiliations.

\section{Author details}

${ }^{1}$ Department of Psychiatry, Columbia University, New York, NY, USA. ${ }^{2}$ Department of Pathology and Cell Biology, Columbia University, New York, NY, USA. ${ }^{3}$ Department of Neurology, Columbia University, New York, NY, USA. ${ }^{4}$ The Taub Institute for Research in Alzheimer's Disease and the Aging Brain, Columbia University, New York, NY, USA.

Received: 25 January 2018 Accepted: 8 February 2018

Published online: 02 March 2018

\section{References}

1. Al-Mashhadi S, Simpson JE, Heath PR, Dickman M, Forster G, Matthews FE, Brayne C, Ince PG, Wharton SB (2015) Oxidative glial cell damage associated with white matter lesions in the aging human brain. Brain pathology (Zurich, Switzerland) 25:565-574. https://doi.org/10.1111/bpa.12216

2. Back SA, Gan X, Li Y, Rosenberg PA, Volpe JJ (1998) Maturation-dependent vulnerability of oligodendrocytes to oxidative stress-induced death caused by glutathione depletion. J Neurosci 18:6241-6253

3. Back SA, Han BH, Luo NL, Chricton CA, Xanthoudakis S, Tam J, Arvin KL, Holtzman DM (2002) Selective vulnerability of late oligodendrocyte progenitors to hypoxia-ischemia. J Neurosci 22:455-463

4. Ballatore C, Lee VM, Trojanowski JQ (2007) Tau-mediated neurodegeneration in Alzheimer's disease and related disorders. Nat Rev Neurosci 8:663-672. https://doi.org/10.1038/nrn2194

5. Bartzokis G (2011) Alzheimer's disease as homeostatic responses to agerelated myelin breakdown. Neurobiol Aging 32: 1341-1371 Doi 0.1016/j. Neurobiolaging.2009.08.007

6. Bartzokis G, Cummings JL, Sultzer D, Henderson W, Nuechterlein KH, Mintz J (2003) White matter structural integrity in healthy aging adults and patients with Alzheimer disease: a magnetic resonance imaging study. Arch Neurol 60:393-398

7. Bartzokis G, Lu PH, Mintz J (2007) Human brain myelination and amyloid beta deposition in Alzheimer's disease. Alzheimers Dement 3:122-125. https://doi.org/10.1016/j.jalz.2007.01.019

8. Bartzokis G, Sultzer D, Lu PH, Nuechterlein KH, Mintz J, Cummings JL (2004) Heterogeneous age-related breakdown of white matter structural integrity: implications for cortical "disconnection" in aging and Alzheimer's disease. Neurobiol Aging 25:843-851. https://doi.org/ 10.1016/j.neurobiolaging.2003.09.005

9. Bateman RJ, Xiong C, Benzinger TL, Fagan AM, Goate A, Fox NC, Marcus DS, Cairns NJ, Xie X, Blazey TMet al (2012) Clinical and biomarker changes in 
dominantly inherited Alzheimer's disease. N Engl J Med 367: 795-804 Doi https://doi.org/10.1056/NEJMoa1202753

10. Baumann N, Pham-Dinh D (2001) Biology of oligodendrocyte and myelin in the mammalian central nervous system. Physiol Rev 81:871-927

11. Behrendt G, Baer K, Buffo A, Curtis MA, Faull RL, Rees Ml, Gotz M, Dimou L (2013) Dynamic changes in myelin aberrations and oligodendrocyte generation in chronic amyloidosis in mice and men. Glia 61:273-286. https://doi.org/10.1002/glia.22432

12. Bender AR, Volkle MC, Raz N (2016) Differential aging of cerebral white matter in middle-aged and older adults: a seven-year follow-up. Neurolmage 125:74-83. https://doi.org/10.1016/j.neuroimage.2015.10.030

13. Benitez A, Fieremans $E$, Jensen JH, Falangola MF, Tabesh A, Ferris SH, Helpern JA (2014) White matter tract integrity metrics reflect the vulnerability of late-myelinating tracts in Alzheimer's disease. Neurolmage Clinical 4:64-71. https://doi.org/10.1016/j.nicl.2013.11.001

14. Bennett DA, Schneider JA, Arvanitakis Z, Kelly JF, Aggarwal NT, Shah RC, Wilson RS (2006) Neuropathology of older persons without cognitive impairment from two community-based studies. Neurology 66:1837-1844. https://doi.org/10.1212/01.wnl.0000219668.47116.e6

15. Bergles DE, Roberts JD, Somogyi P, Jahr CE (2000) Glutamatergic synapses on oligodendrocyte precursor cells in the hippocampus. Nature 405:187-191. https://doi.org/10.1038/35012083

16. Billings LM, Oddo S, Green KN, McGaugh JL, LaFerla FM (2005) Intraneuronal Abeta causes the onset of early Alzheimer's disease-related cognitive deficits in transgenic mice. Neuron 45:675-688. https://doi.org/10.1016/j.neuron.2005.01.040

17. Braak H, Braak E (1996) Development of Alzheimer-related neurofibrillary changes in the neocortex inversely recapitulates cortical myelogenesis. Acta Neuropathol 92:197-201

18. Brickman AM (2013) Contemplating Alzheimer's disease and the contribution of white matter hyperintensities. Curr Neurol Neurosci Rep 13: 415. https://doi.org/10.1007/s11910-013-0415-7

19. Brickman AM, Provenzano FA, Muraskin J, Manly JJ, Blum S, Apa Z, Stern Y, Brown TR, Luchsinger JA, Mayeux R (2012) Regional white matter hyperintensity volume, not hippocampal atrophy, predicts incident Alzheimer disease in the community. Arch Neurol 69:1621-1627. https://doi. org/10.1001/archneurol.2012.1527

20. Brickman AM, Schupf N, Manly JJ, Stern Y, Luchsinger JA, Provenzano FA, Narkhede A, Razlighi Q, Collins-Praino L, Artero S et al (2014) APOE epsilon4 and risk for Alzheimer's disease: do regionally distributed white matter hyperintensities play a role? Alzheimers Dement 10:619-629. https://doi.org/ 10.1016/j.jalz.2014.07.155

21. Brickman AM, Zahodne LB, Guzman VA, Narkhede A, Meier IB, Griffith EY, Provenzano FA, Schupf N, Manly JJ, Stern Y et al (2015) Reconsidering harbingers of dementia: progression of parietal lobe white matter hyperintensities predicts Alzheimer's disease incidence. Neurobiol Aging 36: 27-32. https://doi.org/10.1016/j.neurobiolaging.2014.07.019

22. Brody BA, Kinney HC, Kloman AS, Gilles FH (1987) Sequence of central nervous system myelination in human infancy. I. An autopsy study of myelination. J Neuropathol Exp Neurol 46:283-301

23. Brown WR, Thore CR (2011) Review: cerebral microvascular pathology in ageing and neurodegeneration. Neuropathol Appl Neurobiol 37:56-74. https://doi.org/10.1111/j.1365-2990.2010.01139.x

24. Chittajallu R, Aguirre A, Gallo V (2004) NG2-positive cells in the mouse white and grey matter display distinct physiological properties. J Physiol 561:109122. https://doi.org/10.1113/jphysiol.2004.074252

25. Collins-Praino LE, Francis YI, Griffith EY, Wiegman AF, Urbach J, Lawton A, Honig LS, Cortes E, Vonsattel JP, Canoll PD et al (2014) Soluble amyloid beta levels are elevated in the white matter of Alzheimer's patients, independent of cortical plaque severity. Acta Neuropathol Commun 2:83. https://doi.org/ 10.1186/s40478-014-0083-0 10.1186/preaccept-3091772881321882

26. De Leeuw FE, Barkhof F, Scheltens P (2004) Alzheimer's disease-one clinical syndrome, two radiological expressions: a study on blood pressure. J Neurol Neurosurg Psychiatry 75:1270-1274. https://doi.org/10.1136/jnnp.2003.030189

27. Deng W, Wang H, Rosenberg PA, Volpe JJ, Jensen FE (2004) Role of metabotropic glutamate receptors in oligodendrocyte excitotoxicity and oxidative stress. Proc Natl Acad Sci U S A 101:7751-7756. https://doi. org/10.1073/pnas.0307850101

28. Desai MK, Guercio BJ, Narrow WC, Bowers WJ (2011) An Alzheimer's diseaserelevant presenilin-1 mutation augments amyloid-beta-induced oligodendrocyte dysfunction. Glia 59:627-640. https://doi.org/10.1002/glia. 21131
29. Desai MK, Mastrangelo MA, Ryan DA, Sudol KL, Narrow WC, Bowers WJ (2010) Early oligodendrocyte/myelin pathology in Alzheimer's disease mice constitutes a novel therapeutic target. Am J Pathol 177:14221435. https://doi.org/10.2353/ajpath.2010.100087

30. Desai MK, Sudol KL, Janelsins MC, Mastrangelo MA, Frazer ME, Bowers WJ (2009) Triple-transgenic Alzheimer's disease mice exhibit region-specific abnormalities in brain myelination patterns prior to appearance of amyloid and tau pathology. Glia 57:54-65. https://doi.org/10.1002/glia.20734

31. Erten-Lyons D, Woltjer R, Kaye J, Mattek N, Dodge HH, Green S, Tran H, Howieson DB, Wild K, Silbert LC (2013) Neuropathologic basis of white matter hyperintensity accumulation with advanced age. Neurology 81:977-983. https://doi.org/10.1212/WNL.0b013e3182a43e45

32. Fields RD (2015) A new mechanism of nervous system plasticity: activity-dependent myelination. Nat Rev Neurosci 16:756-767. https://doi.org/10.1038/nrn4023

33. Fischer FU, Wolf D, Scheurich A, Fellgiebel A (2015) Altered whole-brain white matter networks in preclinical Alzheimer's disease. Neurolmage Clinical 8:660-666. https://doi.org/10.1016/j.nicl.2015.06.007

34. French HM, Reid M, Mamontov P, Simmons RA, Grinspan JB (2009) Oxidative stress disrupts oligodendrocyte maturation. J Neurosci Res 87: 3076-3087. https://doi.org/10.1002/jnr.22139

35. Gagyi E, Kormos B, Castellanos KJ, Valyi-Nagy K, Korneff D, LoPresti P, Woltjer R, Valyi-Nagy T (2012) Decreased oligodendrocyte nuclear diameter in Alzheimer's disease and Lewy body dementia. Brain pathology (Zurich, Switzerland) 22:803-810. https://doi.org/10.1111/j.1750-3639.2012.00595.x

36. Gao J, Cheung RT, Lee TM, Chu LW, Chan YS, Mak HK, Zhang JX, Qiu D, Fung G, Cheung C (2011) Possible retrogenesis observed with fiber tracking: an anteroposterior pattern of white matter disintegrity in normal aging and Alzheimer's disease. Journal of Alzheimer's disease : JAD 26:47-58. https://doi.org/10.3233/jad-2011-101788

37. Gogate N, Verma L, Zhou JM, Milward E, Rusten R, O'Connor M, Kufta C, Kim J, Hudson L, Dubois-Dalcq M (1994) Plasticity in the adult human oligodendrocyte lineage. The Journal of neuroscience : the official journal of the Society for Neuroscience 14:4571-4587

38. Gouw AA, Seewann A, Vrenken H, van der Flier WM, Rozemuller JM, Barkhof F, Scheltens P, Geurts JJ (2008) Heterogeneity of white matter hyperintensities in Alzheimer's disease: post-mortem quantitative MRI and neuropathology. Brain : a journal of neurology 131:3286-3298. https://doi.org/10.1093/brain/awn265

39. Holmes C, Boche D, Wilkinson D, Yadegarfar G, Hopkins V, Bayer A, Jones RW, Bullock R, Love S, Neal JWet al (2008) Long-term effects of Abeta42 immunisation in Alzheimer's disease: follow-up of a randomised, placebo-controlled phase I trial. Lancet (London, England) 372: 216-223 Doi https://doi.org/10.1016/s0140-6736(08)61075-2

40. Horiuchi M, Maezawa I, Itoh A, Wakayama K, Jin LW, Itoh T, Decarli C (2012) Amyloid beta1-42 oligomer inhibits myelin sheet formation in vitro. Neurobiol Aging 33:499-509. https://doi.org/10.1016/j.neurobiolaging.2010.05.007

41. Jantaratnotai N, Ryu JK, Kim SU, McLarnon JG (2003) Amyloid beta peptideinduced corpus callosum damage and glial activation in vivo. Neuroreport 14:1429-1433. https://doi.org/10.1097/01.wnr.0000086097.47480.a0

42. Jorgensen AM, Marner $L$, Pakkenberg B (2008) No change in total length of white matter fibers in Alzheimer's disease. Neuroscience 157:878-883. https://doi.org/10.1016/j.neuroscience.2008.06.075

43. Juurlink BH, Thorburne SK, Hertz L (1998) Peroxide-scavenging deficit underlies oligodendrocyte susceptibility to oxidative stress. Glia 22:371-378

44. Kapfhammer JP, Schwab ME (1994) Inverse patterns of myelination and GAP-43 expression in the adult CNS: neurite growth inhibitors as regulators of neuronal plasticity? J Comp Neurol 340:194-206. https://doi.org/10.1002/cne.903400206

45. Kelleher RJ 3rd, Shen J (2017) Presenilin-1 mutations and Alzheimer's disease. Proc Natl Acad Sci U S A 114:629-631. https://doi.org/10.1073/pnas.1619574114

46. Kukley M, Capetillo-Zarate E, Dietrich D (2007) Vesicular glutamate release from axons in white matter. Nat Neurosci 10:311-320. https:// doi.org/10.1038/nn1850

47. Lebel C, Beaulieu C (2011) Longitudinal development of human brain wiring continues from childhood into adulthood. J Neurosci 31:1093710947. https://doi.org/10.1523/jneurosci.5302-10.2011

48. Lee JT, Xu J, Lee JM, Ku G, Han X, Yang DI, Chen S, Hsu CY (2004) Amyloidbeta peptide induces oligodendrocyte death by activating the neutral sphingomyelinase-ceramide pathway. J Cell Biol 164:123-131. https://doi. org/10.1083/jcb.200307017 
49. Lee S, Viqar F, Zimmerman ME, Narkhede A, Tosto G, Benzinger TL, Marcus DS, Fagan AM, Goate A, Fox NC et al (2016) White matter hyperintensities are a core feature of Alzheimer's disease: evidence from the dominantly inherited Alzheimer network. Ann Neurol 79:929-939. https://doi.org/10.1002/ana.24647

50. Marner L, Nyengaard JR, Tang Y, Pakkenberg B (2003) Marked loss of myelinated nerve fibers in the human brain with age. J Comp Neurol 462: 144-152. https://doi.org/10.1002/cne.10714

51. Marques S, Zeisel A, Codeluppi S, van Bruggen D, Mendanha Falcao A, Xiao L, Li H, Haring M, Hochgerner H, Romanov RAet al (2016) Oligodendrocyte heterogeneity in the mouse juvenile and adult central nervous system. Science (New York, NY) 352: 1326-1329 Doi https://doi.org/10.1126/science. aaf6463

52. Mason JL, Langaman C, Morell P, Suzuki K, Matsushima GK (2001) Episodic demyelination and subsequent remyelination within the murine central nervous system: changes in axonal calibre. Neuropathol Appl Neurobiol 27: 50-58

53. Matute C (2010) Calcium dyshomeostasis in white matter pathology. Cell Calcium 47:150-157. https://doi.org/10.1016/j.ceca.2009.12.004

54. Matute C (2006) Oligodendrocyte NMDA receptors: a novel therapeutic target. Trends Mol Med 12:289-292. https://doi.org/10.1016/j.molmed.2006. 05.004

55. Matute C, Alberdi E, Domercq M, Sanchez-Gomez MV, Perez-Samartin A, Rodriguez-Antiguedad A, Perez-Cerda F (2007) Excitotoxic damage to white matter. J Anat 210:693-702. https://doi.org/10.1111/j.1469-7580.2007.00733.x

56. McAleese KE, Firbank M, Dey M, Colloby SJ, Walker L, Johnson M, Beverley JR, Taylor JP, Thomas AJ, O'Brien JT et al (2015) Cortical tau load is associated with white matter hyperintensities. Acta neuropathologica communications 3:60. https://doi.org/10.1186/s40478-015-0240-0

57. McAleese KE, Walker L, Graham S, Moya EL, Johnson M, Erskine D, Colloby SJ, Dey M, Martin-Ruiz C, Taylor JP et al (2017) Parietal white matter lesions in Alzheimer's disease are associated with cortical neurodegenerative pathology, but not with small vessel disease. Acta neuropathologica. https://doi.org/10.1007/s00401-017-1738-2

58. McKenzie IA, Ohayon D, Li H, de Faria JP, Emery B, Tohyama K, Richardson WD (2014) Motor skill learning requires active central myelination. Science (New York, NY) 346:318-322. https://doi.org/10.1126/science.1254960

59. Menn B, Garcia-Verdugo JM, Yaschine C, Gonzalez-Perez O, Rowitch D, Alvarez-Buylla A (2006) Origin of oligodendrocytes in the subventricular zone of the adult brain. J Neurosci 26:7907-7918. https://doi.org/10.1523/ jneurosci.1299-06.2006

60. Pak K, Chan SL, Mattson MP (2003) Presenilin-1 mutation sensitizes oligodendrocytes to glutamate and amyloid toxicities, and exacerbates white matter damage and memory impairment in mice. NeuroMolecular Med 3:53-64. https://doi.org/10.1385/nmm:3:1:53

61. Pantoni L, Garcia JH (1997) Cognitive impairment and cellular/vascular changes in the cerebral white matter. Ann N Y Acad Sci 826:92-102

62. Price JL, McKeel DW Jr, Buckles VD, Roe CM, Xiong C, Grundman M, Hansen LA, Petersen RC, Parisi JE, Dickson DW et al (2009) Neuropathology of nondemented aging: presumptive evidence for preclinical Alzheimer disease. Neurobiol Aging 30:1026-1036. https://doi.org/10.1016/j. neurobiolaging.2009.04.002

63. Prins ND, Scheltens $P$ (2015) White matter hyperintensities, cognitive impairment and dementia: an update. Nat Rev Neurol 11:157-165. https://doi.org/10.1038/nrneurol.2015.10

64. Raz N, Yang Y, Dahle CL, Land S (2012) Volume of white matter hyperintensities in healthy adults: contribution of age, vascular risk factors, and inflammation-related genetic variants. Biochim Biophys Acta 1822:361369. https://doi.org/10.1016/j.bbadis.2011.08.007

65. Reisberg B, Franssen EH, Hasan SM, Monteiro I, Boksay I, Souren LE, Kenowsky S, Auer SR, Elahi S, Kluger A (1999) Retrogenesis: clinical, physiologic, and pathologic mechanisms in brain aging, Alzheimer's and other dementing processes. Eur Arch Psychiatry Clin Neurosci 249(Suppl 3):28-36

66. Reisberg B, Franssen EH, Souren LE, Auer SR, Akram I, Kenowsky S (2002) Evidence and mechanisms of retrogenesis in Alzheimer's and other dementias: management and treatment import. Am J Alzheimers Dis Other Demen 17:202-212. https://doi.org/10.1177/153331750201700411

67. Roher AE, Weiss N, Kokjohn TA, Kuo YM, Kalback W, Anthony J, Watson D, Luehrs DC, Sue L, al WD (2002) Increased a beta peptides and reduced cholesterol and myelin proteins characterize white matter degeneration in Alzheimer's disease. Biochemistry 41:11080-11090
68. Scheltens P, Barkhof F, Leys D, Wolters EC, Ravid R, Kamphorst W (1995) Histopathologic correlates of white matter changes on MRI in Alzheimer's disease and normal aging. Neurology 45:883-888

69. Schuff N, Matsumoto S, Kmiecik J, Studholme C, Du A, Ezekiel F, Miller BL, Kramer JH, Jagust WJ, Chui HC et al (2009) Cerebral blood flow in ischemic vascular dementia and Alzheimer's disease, measured by arterial spinlabeling magnetic resonance imaging. Alzheimers Dement 5:454-462. https://doi.org/10.1016/j.jalz.2009.04.1233

70. Schwab ME (1990) Myelin-associated inhibitors of neurite growth and regeneration in the CNS. Trends Neurosci 13:452-456

71. Scott JA, Braskie MN, Tosun D, Thompson PM, Weiner M, DeCarli C, Carmichael OT (2015) Cerebral amyloid and hypertension are independently associated with white matter lesions in elderly. Front Aging Neurosci 7:221. https://doi.org/10.3389/fnagi.2015.00221

72. Selkoe DJ (2011) Resolving controversies on the path to Alzheimer's therapeutics. Nat Med 17:1060-1065. https://doi.org/10.1038/nm.2460

73. Selkoe DJ, Hardy J (2016) The amyloid hypothesis of Alzheimer's disease at 25 years. EMBO Mol Med 8:595-608. https://doi.org/10.15252/emmm.201606210

74. Simpson JE, Fernando MS, Clark L, Ince PG, Matthews F, Forster G, O'Brien JT, Barber R, Kalaria RN, Brayne C et al (2007) White matter lesions in an unselected cohort of the elderly: astrocytic, microglial and oligodendrocyte precursor cell responses. Neuropathol Appl Neurobiol 33:410-419. https://doi.org/10.1111/j.1365-2990.2007.00828.x

75. Sims R, Hollingworth P, Moskvina V, Dowzell K, O'Donovan MC, Powell J, Lovestone S, Brayne C, Rubinsztein D, Owen MJ et al (2009) Evidence that variation in the oligodendrocyte lineage transcription factor 2 (OLIG2) gene is associated with psychosis in Alzheimer's disease. Neurosci Lett 461:54-59. https://doi.org/10.1016/j.neulet.2009.05.051

76. Stricker NH, Schweinsburg BC, Delano-Wood L, Wierenga CE, Bangen K, Haaland KY, Frank LR, Salmon DP, Bondi MW (2009) Decreased white matter integrity in late-myelinating fiber pathways in Alzheimer's disease supports retrogenesis. Neurolmage 45:10-16. https://doi.org/10.1016/j.neuroimage.2008.11.027

77. Thorburne SK, Juurlink BH (1996) Low glutathione and high iron govern the susceptibility of oligodendroglial precursors to oxidative stress. J Neurochem 67:1014-1022

78. Tosto G, Zimmerman ME, Carmichael OT, Brickman AM (2014) Predicting aggressive decline in mild cognitive impairment: the importance of white matter hyperintensities. JAMA neurology 71:872-877. https://doi.org/10. 1001/jamaneurol.2014.667

79. Tosto G, Zimmerman ME, Hamilton JL, Carmichael OT, Brickman AM (2015) The effect of white matter hyperintensities on neurodegeneration in mild cognitive impairment. Alzheimers Dement 11:1510-1519. https://doi.org/10. 1016/j.jalz.2015.05.014

80. Tsai HH, Niu J, Munji R, Davalos D, Chang J, Zhang H, Tien AC, Kuo CJ, Chan $J R$, Daneman R et al (2016) Oligodendrocyte precursors migrate along vasculature in the developing nervous system. Science (New York, NY) 351: 379-384. https://doi.org/10.1126/science.aad3839

81. Tse KH, Herrup K (2017) DNA damage in the oligodendrocyte lineage and its role in brain aging. Mech Ageing Dev 161:37-50. https://doi. org/10.1016/j.mad.2016.05.006

82. Tse KH, Herrup K (2017) Re-imagining Alzheimer's disease - the diminishing importance of amyloid and a glimpse of what lies ahead. J neurochemistry. https://doi.org/10.1111/jnc.14079

83. Vlkolinsky R, Cairns N, Fountoulakis M, Lubec G (2001) Decreased brain levels of 2',3'-cyclic nucleotide-3'-phosphodiesterase in down syndrome and Alzheimer's disease. Neurobiol Aging 22:547-553

84. Xu J, Chen S, Ahmed SH, Chen H, Ku G, Goldberg MP, Hsu CY (2001) Amyloid-beta peptides are cytotoxic to oligodendrocytes. The journal of neuroscience : the official journal of the Society for Neuroscience 21: Rc118

85. Yuen TJ, Silbereis JC, Griveau A, Chang SM, Daneman R, Fancy SP, Zahed H, Maltepe E, Rowitch DH (2014) Oligodendrocyte-encoded HIF function couples postnatal myelination and white matter angiogenesis. Cell 158:383396. https://doi.org/10.1016/j.cell.2014.04.052

86. Zhao Z, Nelson AR, Betsholtz C, Zlokovic BV (2015) Establishment and dysfunction of the blood-brain barrier. Cell 163:1064-1078. https://doi. org/10.1016/j.cell.2015.10.067 